\title{
Landmark-based geometric morphometric analysis of body shape variation within population of Ibis fish, Ambassis interrupta, collected from Masao River, Butuan City, Philippines
}

\author{
Mary Grace T. Medrano and Joycelyn C. Jumawan
}

\begin{abstract}
Masao River Butuan City, Mindanao, Philippines is home to many organisms especially those associated with the freshwater communities. Fishes were abundantly present including one of the commercially important fishes, the Ambassis interrupta, locally known as "ibis". This study describes the variation in body shapes of $A$. interrupta using landmark-based geometric morphometric analysis. A total of 100 fish samples, collected from Masao River, Butuan City were digitized using sixteen landmark points. This study also determines the variations in the patterns of fluctuating asymmetry (FA) in a total of sixteen bilateral traits of $A$.interrupta. FA can be a helpful tool in measuring stress because an organism's ability to cope with genetic and environmental stress during development is manifested through FA measures. The Procrustes ANOVA showed differences in the patterns of asymmetry between sexes of the fishes. Three factors were analyzed for FA and these were: individuals, sides, and interaction of individuals and sides. The individual symmetry among the fish samples showed no significant differences, while the sides and interaction of individuals and sides showed a highly significant difference $(\mathbf{P}<0.0001)$. This could be due to the presence of fish ponds, application of feeds and communities dwelling along Masao River which may affect the physical and chemical condition of the river. This may also affect the overall phenotype of the fish. The results implied asymmetry in the left and right side of each sample, also in the interaction of individuals and sides. However, the individuals were symmetrical with each other. Principal Component Analysis revealed that the five significant principal components (PC1-PC5) contribute most to the variation that exist among individuals. A total of $71.46 \%$ of the variation exist in the FA interaction in female fish and a total of $62.04 \%$ is observed in the FA interaction in male fish. The results however indicate that fluctuating asymmetry are higher compared to individual variation in females, but individual variation is higher compared to fluctuating asymmetry in males.
\end{abstract}

Keywords-Ambassis interrupta, ibis, fish shape, geometric morphometrics, fluctuating asymmetry, landmarks, Masao River

Manuscript received March 29, 2016

M. T. Medrano is a College Instructor at Father Saturnino Urios University, Butuan City, Philippines. She is with the Natural Science and Mathematics Division, Arts and Sciences Program. Currently, she is a graduate student at Caraga State University, Butuan City. She is taking up PhD Science Education.

J. C. Jumawan is an Associate Professor at Caraga State University. She finished PhD Biology at University of the Philippines, Diliman, Quezon City.

\section{INTRODUCTION}

The comparisons on the anatomical attributes of organisms have long been considered as the central component of Biology. The organisms' morphological accounts and descriptions turned out to be the basis underpinning the understanding of life as well as the organisms' classification [1]. Jaranilla et al. [2] wrote that there is a crisis in the taxonomic identification of organisms and there is a challenge in cataloguing the Earth's vast array of organisms. This predicament resulted to the birth of prospective technology to bring out a quick response on the identification dilemmas. The technologies made for this purpose include Computer-based automated species recognition. Among the automated species recognition systems developed recently, the use of geometric morphometric-based techniques were frequently utilized by many. Geometric morphometric (GM) analysis was successfully applied by Rolhf [3] and Adams et al. [1] in their study on differentiating the shape variation in Bluefin tuna. Conversely, Addis [4] also used GM in rainbow trout. Geometric morphometric analyses were also employed on the following organisms on study: rice bug [5], white goby [6], Aedes aegypti [7], and American sailfin catfish [2].

According to Sheets [8], morphometrics can be employed to a variety of quantitative investigations such as on biological shape, shape disparity, and covariation of shape with other biotic or abiotic variables or factors. The much-needed meticulousness into the description between organisms' morphologies is introduced through the exactitude in the quantifications in morphometrics. The application of such techniques benefits many research field on comparative morphology.

Organisms are capable of making adaptations that enable them to survive. Fishes, like other organism exhibit similar characteristics as well [9]. During the developmental history or ontogeny of an organism, its morphology modeling is greatly influenced by its environment [10].

Fishes could be exposed to different environmental conditions. According to Parsons [11], fluctuating asymmetry (FA) is a sensitive indicator of developmental stress. Increased FA is a result to both the genetic (e.g. inbreeding, hybridization, spread of new mutants) and environmental (e.g. $\mathrm{pH}$, temperature, pollutants) influences. As a result, FA has 
been promoted as a useful measure of well-being at both the individual and population levels. FA was also proposed useful proxy for fitness [12].

The Masao River in Butuan City Philippines is known to be the home to many organisms especially those associated with the freshwater communities. Fishes were abundantly present such as the commercially abundant species, Ambassis interrupta, locally known as "Ibis". The present study determines the body shape variation of Ibis using landmark-based geometric morphometric analysis collected from Masao River, Butuan City, Philippines. Also, this study determines the variations in the patterns of fluctuating asymmetry in a total of sixteen bilateral traits of Ambassis interrupta. The information gathered from this study would imply that FA can be used as a measure of genetic and/or environmental stress and at the same time provides useful information on the nature and variation of $A$. interrupta.

\section{MATERIALS AND METHODS}

\section{A. Study Area}

The study was conducted in the selected areas along the Masao River and was employed during the last week of December 2015. Masao River is located 9 $0^{\circ} 0^{\prime}$ " $\mathrm{N}$ and 12528'59.99" E, part of Barangay Masao, Butuan City, Philippines. Mapping was obtained through Global Positioning System (GPS) by the use of an online mapping (http://maps.google.com) shown in Fig. 1. The river is the source of a variety of economically important fishes which serve as the source of livelihood to local fishermen. It is also one of the tributaries of Agusan River.

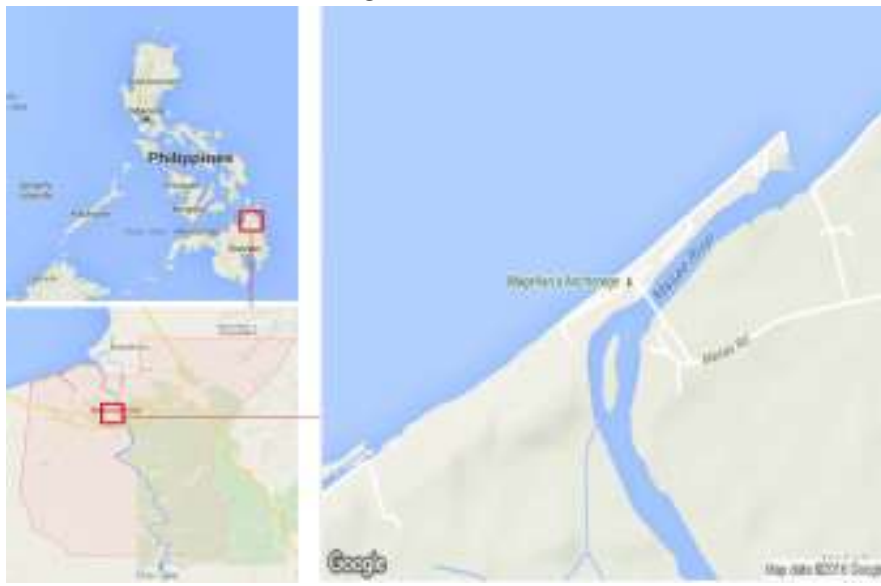

Fig. 1. The Geographical location of the study site. (Map of the Philippines (left above) showing Mindanao area pointing Butuan City (left below), showing Masao River (right).

\section{B. Fish sample collection and digital image preparation}

A total of 100 Ibis fish samples (50 males and 50 females) were collected from the site mentioned above. The fish specimens were sacrificed by cold torpor and the fins were stiffened using a $10 \%$ formalin solution [13]. The samples were photographed using a digital camera, and high resolution images of the lateral views (right and left sides) were kept on file. Sexes of the specimens were determined by direct examination of the gonads. Female fish has yellowish and granular texture gonads while male fish has whitish and non-granular gonads [14].

\section{Landmark selection and digitization of sample images}

A total of 16 landmarks were digitized using tpsDig2 program version 2.0 [15] and were saved to TPS files. The location of the landmarks and the anatomical descriptions of each are presented in Fig. 2 and Table I. The descriptions of the landmark points are based on Sparks and Chakrabarty [16].

\section{Fluctuating asymmetry analysis}

Overall and localized fluctuating asymmetries were determined by subjecting the paired landmark coordinates to Procrustes ANOVA following the method of Klingenberg (1998) and using the SAGE software version 1.0 [17].
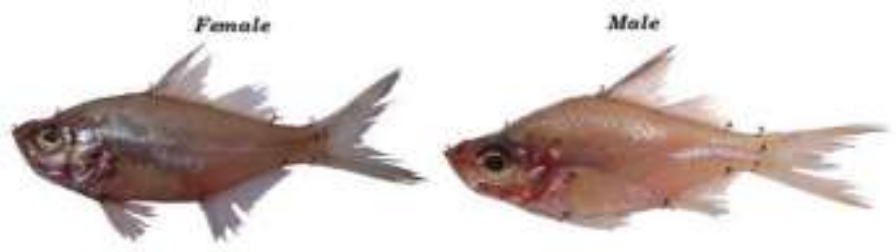

Fig. 2. The location of the landmarks used for geometric morphometric analysis.

TABLE I: DESCRIPTION OF THE LANDMARK POINTS ACCORDING TO SPARKS AND CHAKRABARTY (2007).

\begin{tabular}{cl} 
Coordinates & \multicolumn{1}{c}{ Location } \\
\hline 1 & Rostral tip of premaxilla \\
2 & Posterior end of nuchal spine \\
3 & Anterior insertion of dorsal fin \\
4 & Posterior insertion of dorsal fin \\
5 & Dorsal insertion of caudal fin \\
6 & Midpoint or lateral line \\
7 & Ventral insertion of caudal fin \\
8 & Posterior insertion of anal fin \\
9 & Anterior insertion of anal fin \\
10 & Dorsal base of pelvic fin \\
11 & Ventral end of lower jaw articulation \\
12 & Posterior end of the premaxilla \\
13 & Anterior margin through midline of orbit \\
14 & Posterior margin through midline of orbit \\
15 & Dorsal end of opercle \\
16 & Dorsal base of pectoral fin \\
\hline \hline
\end{tabular}

\section{RESULTS AND DISCUSSION}

Landmark-based geometric morphometric analysis was used to describe the body shape variation that exists among Ambassis interrupta fish samples from Masao River, Butuan City, Philippines. Also, Fluctuating asymmetry (FA) refers to small random deviations from perfect symmetry in bilaterally paired structures [11]. An organism's ability to cope with genetic and environmental stress during development is manifested through the FA measures. A fundamental premise of FA analysis is that identical genes influence the development of the two sides of a bilaterally symmetrical organism and thus, 
the present physical traits of an organism reflect accidents occurring during development [19].

In this study, the Procrustes ANOVA suggested evidence in two of the factors considered within the two sexes of Ambassis interrupta (Table II). Both the left and the right sides were analyzed to compare its fluctuating asymmetry. Three factors were analyzed for FA and these were individuals, sides, and interaction of individuals and sides. The individual symmetry among the fish samples showed no significant differences, while the sides and interaction of individuals and sides showed a highly significant difference $(\mathrm{P}<0.0001)$. The results implied asymmetry in sides, which is the left and right side of each sample, also in interaction of individuals and sides. However, the individuals were symmetrical with each other.

The presence of fish ponds, application of feeds and communities dwelling along the Masao River, may possibly affect the physical and chemical condition of the river. This may be the reason why there is a high significant difference between the sides and interaction of individuals and sides of the Ambassis interrupta samples. Poor water quality is a result on the perturbations on the environment [20], which in turn may affect the fishes' morphological attributes. In this study, the results obviously imply that the sides and interaction of individuals and sides' highly significant asymmetry measures could possibly be the result of the anthropogenic activities observed in the Masao River.

TABLE II: PROCRUSTES ANOVA RESULTS OF IBIS, AMBASSIS INTERRUPTA FISH COLLECTED FROM MASARO RIVER, BUTUAN CITY, PHILIPPINES.

\begin{tabular}{lcllll}
\hline \hline \multicolumn{1}{c}{ Effect } & SS & \multicolumn{1}{c}{ dF } & MS & \multicolumn{1}{c}{ F } & \multicolumn{1}{c}{ P-value } \\
\hline Individuals & 0.243 & 1204 & 0.0002 & 0.9878 & 0.5842 \\
Sides & 0.091 & 28 & 0.0032 & 15.8486 & $0.0001^{* *}$ \\
Individuals x Sides & 0.246 & 1204 & 0.0002 & 7.6884 & $0.0001^{* *}$ \\
Measurement Error & 0.131 & 4928 & 0 & -- & -- \\
\multicolumn{7}{c}{ Male } \\
Individuals & 0.219 & 1204 & 0.0002 & 1.1331 & 0.0151 \\
Sides & 0.014 & 28 & 0.0005 & 3.0076 & $0.0001^{* *}$ \\
Individuals x Sides & 0.193 & 1204 & 0.0002 & 6.2267 & $0.0001^{* *}$ \\
Measurement Error & 0.127 & 4928 & 0 & -- & -- \\
\hline \hline
\end{tabular}

$* *(\mathrm{P}<0.0001)$ highly significant

The differences between population means, or the deviation an individual from its population mean are visualized in at least two ways by the landmark data. An alternative way to inspect the variability of landmark points in tangent space is to run a principal component analysis (PCA) on the tangent coordinates derived from Procrustes analysis [17]. The result of the Principal Component Analysis (PCA) is shown in Table III. A total of $71.4559 \%$ in female of FA interaction from upper 5\% effective principal components (PC1-PC5) is measured. According to the results in PC1, asymmetry can be found greatest in the area covered by landmark: 1 (snout tip), 2 (posterior end of nuchal spine), 3 (anterior insertion of dorsal fin), 4 (posterior insertion of dorsal fin), 5 (dorsal insertion of caudal fin ), 6 (midpoint), 7 (ventral insertion of caudal fin ), 9 (anterior insertion of anal fin ), 10 (dorsal base of pelvic fin), 11 (ventral end of lower jaw articulation), 12 (posterior end of premaxilla), 15 (dorsal end of operlce), 16 (dorsal base of pectoral fin). FA can also be seen among males with a total of $62.0359 \%$ FA interaction that shows movement of landmarks on the different regions depicted on the following landmarks 1,2,3,5,6,7,8,9,10,11,14,15,16; which are: 1 (snout tip), 2 (posterior end of nuchal spine), 3 (anterior insertion of dorsal fin), 5 (dorsal insertion of caudal fin), 6 (midpoint), 7 (ventral insertion of caudal fin ), 8 (posterior insertion of anal fin ), 9 (anterior insertion of anal fin ), 10 (dorsal base of pelvic fin), 11 (ventral end of lower jaw articulation), 14 (Posterior margin through midline of orbit), 15 (dorsal end of operlce), and 16 (dorsal base of pectoral fin).

TABLE III: PRINCIPAL COMPONENT SCORES SHOWING THE VALUES OF SYMMETRY AND ASYMMETRY SCORES WITH THE SUMMARY OF THE AFFECTED LANDMARKS.

\begin{tabular}{|c|c|c|c|c|}
\hline PCA & $\begin{array}{l}\text { Individual } \\
\text { (Symmetry) }\end{array}$ & $\begin{array}{c}\text { Sides } \\
\text { (Directional } \\
\text { Symmetry) } \\
\end{array}$ & $\begin{array}{c}\text { Interaction } \\
\text { (Fluctuating } \\
\text { Asymmetry) }\end{array}$ & $\begin{array}{c}\text { Affected } \\
\text { Landmarks }\end{array}$ \\
\hline \multicolumn{5}{|c|}{ Female } \\
\hline $\mathrm{PC} 1$ & $23.5265 \%$ & $100 \%$ & $32.546 \%$ & $\begin{array}{c}1,2,3,4,5,6,7,9,10 \\
, 11,12,15,116\end{array}$ \\
\hline $\mathrm{PC} 2$ & $13.5964 \%$ & \multirow{11}{*}{$100 \%$} & $16.3056 \%$ & $\begin{array}{c}1,2,3,4,5,6,7,9,10 \\
, 11,13,14,15,16\end{array}$ \\
\hline $\mathrm{PC} 3$ & $11.3927 \%$ & & $9.6969 \%$ & $\begin{array}{l}1,2,3,5,6,8,9,10,1 \\
1,12,13,14,15,16\end{array}$ \\
\hline PC4 & $9.039 \%$ & & $6.5752 \%$ & $\begin{array}{c}1,2,4,5,6,7,9,10,1 \\
5,16\end{array}$ \\
\hline \multirow[t]{2}{*}{ PC5 } & $7.2938 \%$ & & $6.3322 \%$ & \multirow[t]{2}{*}{$2,3,4,7,8,9,10$} \\
\hline & $64.8484 \%$ & & $71.4559 \%$ & \\
\hline \multicolumn{5}{|c|}{ Male } \\
\hline $\mathrm{PC} 1$ & $28.1106 \%$ & & $20.8827 \%$ & $\begin{array}{c}1,2,3,5,6,7,8,9,10 \\
, 11,14,15,16\end{array}$ \\
\hline $\mathrm{PC} 2$ & $15.0133 \%$ & & $14.6327 \%$ & $\begin{array}{c}2,4,5,8,9,11,12,1 \\
3,14,16\end{array}$ \\
\hline $\mathrm{PC} 3$ & $10.744 \%$ & & $10.2797 \%$ & $\begin{array}{c}1,2,3,4,7,8,9,15,1 \\
6\end{array}$ \\
\hline PC4 & $7.3248 \%$ & & $8.6627 \%$ & $\begin{array}{c}2,3,4,6,7,8,11,15 \\
16\end{array}$ \\
\hline \multirow[t]{2}{*}{ PC5 } & $7.102 \%$ & & $7.5781 \%$ & $3,4,8,9,10,11,15$ \\
\hline & $68.2947 \%$ & & $62.0359 \%$ & \\
\hline
\end{tabular}

The most affected landmarks, (female samples) are exhibited by all except those found in landmarks $8,11,12,13$, and 14 . The asymmetry is greatest at the rostral tip of premaxilla of the female samples followed by the Posterior end of nuchal spine, anterior insertion of anal fin and the dorsal base of pelvic fin which ranked the second highest in asymmetry results. The anterior insertion of dorsal fin, posterior insertion of dorsal fin, dorsal insertion of caudal fin, midpoint of lateral line, ventral insertion of caudal fin, ranked the third showing movement of the landmarks. This explains the PCA measures of $71.4559 \%$ in female of FA interaction; showing that almost entirely all landmarks throughout the A. interrupta fish body were affected by variations. These parts were mostly used for the fish's mobility and food procurement, typically those used for activities mostly subjected to environmental stresses.

Among the male Ambassis interrupta samples, the most commonly affected landmarks were 1, 8, 2, 3, 4, 9, and 15 respectively. These parts were considered an advantage in determining direct impact of stressors in the fish [21].

To visualize the actual affected landmarks, Figs. 3 and 4 
show the actual digitized image of female and male fishes with PCA deformation grid. The distribution of asymmetrical shape of A. interrupta and the locations of the greatest asymmetry are also shown in these figures. In this study, the morphological landmark was represented by dots while the direction and the magnitude of the fluctuation were denoted by an arrow. The encircled dots indicated the movement of the highest affected landmarks and regions emphasized that there were differences in the shape of A. interrupta (Fig. 5).
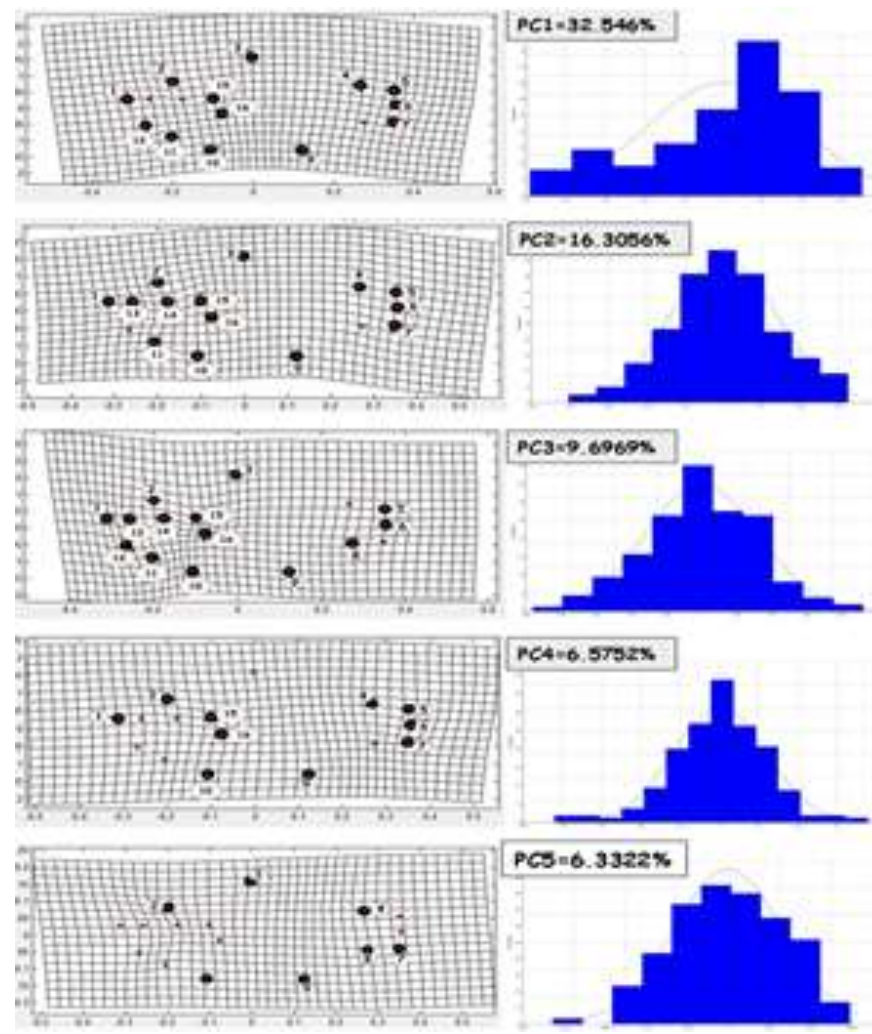

Fig. 3. Principal components (PC) implied deformation grid and histogram of individual (symmetric) in ibis (Ambassis interrupta) fish species showing distribution of asymmetry. The percentages indicate the proportions of variation for which the respective principal components account.
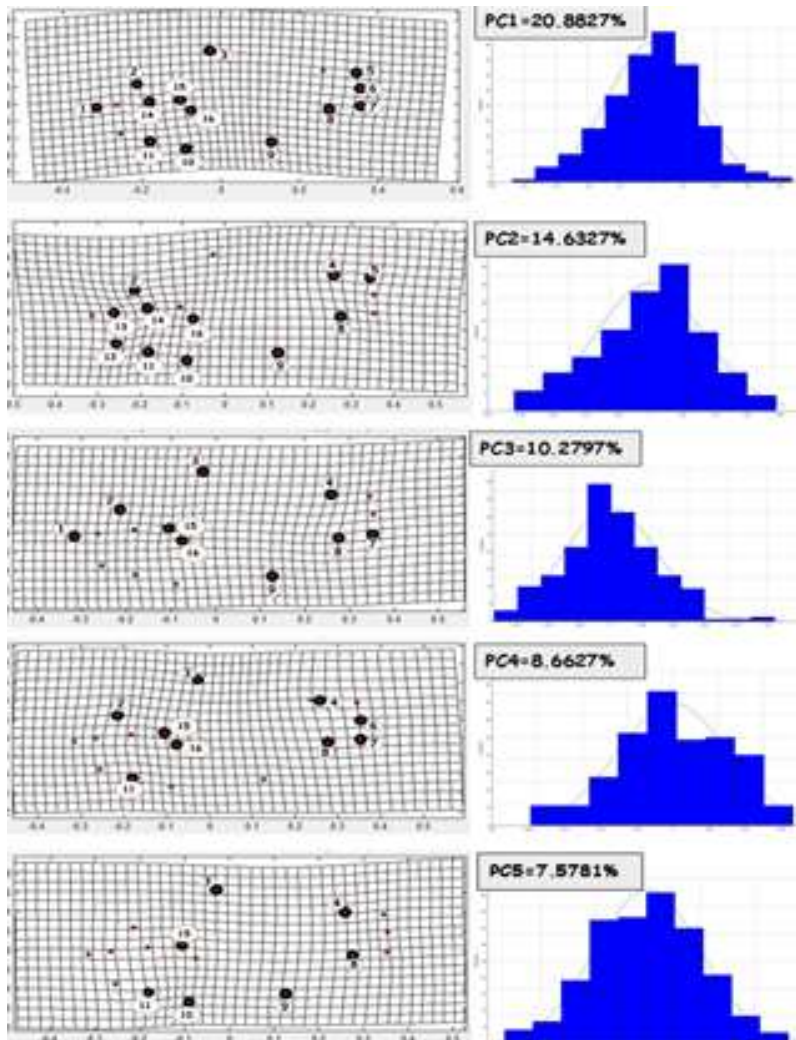

Fig. 4. Principal components (PC) implied deformation grid and histogram of individual (symmetric) in IBIS fish male species.
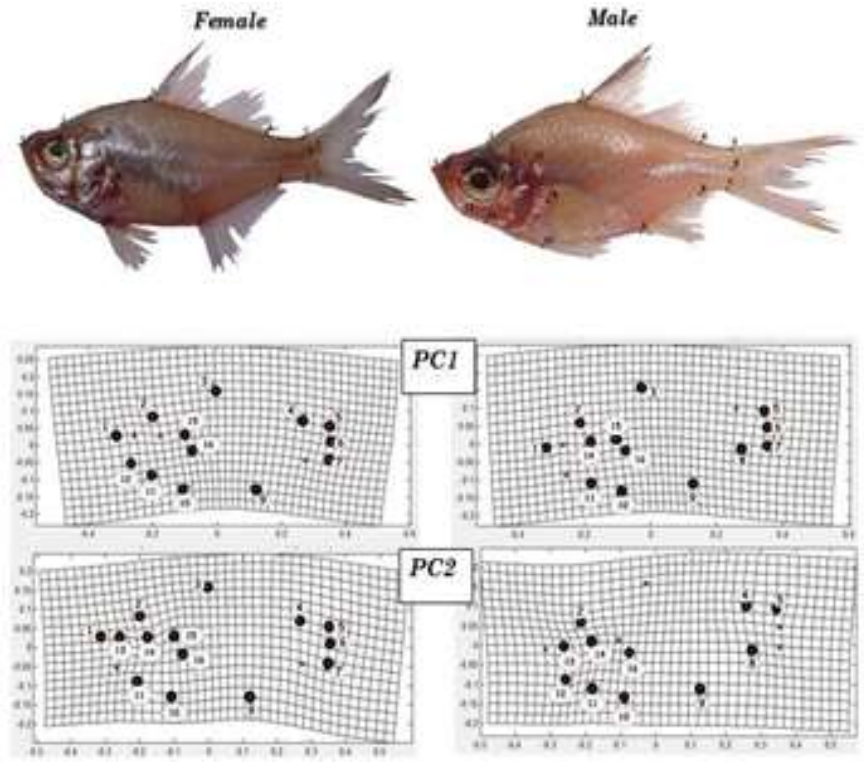

Fig. 5. The highest affected landmarks in Ambassis interrupta.

\section{CONCLUSION}

This study demonstrates that landmark-based geometric morphometric analysis can be used to determine body shape variation in ibis (Ambassis interrupta) fish samples. In this study, the first five principal components summarized the variation that existed in A. interrupta collected from Masao River, Butuan City. Also, the use of fluctuating asymmetry (FA) can be a helpful tool in measuring stress, because an 
organism's ability to cope with genetic and environmental stress during development is manifested through the FA measures. It is clearly manifested in this study that the sides and interaction of individuals and sides showed a highly significant difference $(\mathrm{P}<0.001)$. This could be possibly attributed to the presence of fish ponds, application of feeds and communities dwelling along the Masao River that could have affected the physical and chemical condition of the river, which could in turn affect the overall phenotype of the fish.

\section{ACKNOWLEDGMENT}

The authors are grateful to Loren Grace J. Anunciado for the assistance in completing this paper; and to Ms. Candy Claire Deloso for the analysis of the data. Also, the authors would like to thank the barangay officials of Barangay Masao, Butuan City for granting us permit in conducting the study.

\section{REFERENCES}

[1] Adams, D.C., Rohlf, F.J., Slice, D., 2004. Geometric morphometrics: ten years of progress following the 'revolution'. Italian Journal of Zoology 71:5-16.

http://dx.doi.org/10.1080/11250000409356545

[2] Jaranilla, LG., 2010. Describing variability in head shapes in three populations of american sailfin catfish (Pterygoplichthys spp.) using geometric morphometric analysis De La Salle University - Manila, Philippines

[3] Rohlf, F. J. 2002. Geometric morphometrics and phylogeny.Pp. 175-193 in N. MacLeod and P. L. Forey, eds. Morpholgy, shape and phylogeny. Taylor and Francis, London.

[4] Addis, P., Melis, P., Cannas, R., Secci, M., Tinti, F., Piccinetti, C., \&Cau, A. 2010. A morphometric approach for the analysis of body shape in bluefin tuna : preliminary results. Collect. Vol. Sci. Pap 65(3): 982987.

[5] Torres, M., Lumansoc, J., and Demayo, C., 2010. Variability in head shapes in three populations of the Rice Bug Leptocorisa oratorius (Fabricius) (Hemiptera: Alydidae) Egypt. Acad. J. biolog. Sci., 3 (1): 173 - 184. A. Entomology

[6] Dorado, E., Torres, M., and Demayo, C., 2012. Describing body shapes of the white goby, Glossogobius giuris of Lake Buluan in Mindanao, Philippines using landmark-based geometric morphometric analysis. International Research Journal of Biological Sciences Vol. 1(7), 33-37, I. Res. J. Biological Sci.

[7] Sendaydiego, J., Torres, M., and Demayo, C., 2013. Describing Wing Geometry of Aedes Aegypti Using Landmark-Based Geometric Morphometrics. International Journal of Bioscience, Biochemistry and Bioinformatics, Vol. 3, No. 4.

[8] Sheets and Webster 2001. A practical introduction to Landmark- based geometric morphometrics. In Quantitative Methods in Paleobiology, pp. 163-188, Paleontological Society Short Course, October 30th, 2010. The Paleontological Society Papers, Volume 16, John Alroy and Gene Hunt (eds.).

[9] Nacua, S, Dorado, E., Torres, M., and Demayo, C. 2010. Body Shape Variation Between Two Populations of the White Goby, Glossogobius giuris (Hamilton and Buchanan) Research Journal of Fisheries and Hydrobiology, 5(1): 44-51, INSInet Publication

[10] Costa, C., Cataudella, S., 2007. Relationship between shape and tropic ecology of selected species of Sparids of the Caprolace coastal lagoon (Central Tyrrhenian sea). Environmental Biology of fishes 78:115-123. http://dx.doi.org/10.1007/s10641-006-9081-9

[11] Parsons, P. A., 1990. Fluctuating asymmetry: an epigenetic measure of stress. Biological Reviews 65:131-145. http://dx.doi.org/10.1111/j.1469-185X.1990.tb01186.x

[12] Clarke, G.M., 1995. Relationship between developmental stability and fitness: application for conservation biology. Conserve Biol. 9 (1), 18-24, doi: 10.1046/j. 1523- 1739.1995.09010018x.

[13] Love, J.W., Chase, P.D. 2009. Geometric Morphological Differences Distinguish Populations of Scup in the Northwestern Atlantic Ocean.
Marine and Coastal Fisheries: Dynamics, Management, and Ecosystem science $1: 22-28$

http://dx.doi.org/10.1577/C08-023.1

[14] Requieron, E., Manting, M. M., Torres, M. A. J., Demayo, C. G. 2010. Body shape variation among three congeneric species of pony fishes (Teleostei: Perciformes: Leiognathidae). Transactions of the National Academy of Science and Technology 32(1):49-50.

[15] Rohlf, F.J., 2004. Thin-plate spline, digitize landmarks and outlines, version 1.20. Dept Ecol. \&Evol., St. Univ. New York, Stony Brook, New York.

[16] Chakrabarty P., Amarangsinghe T., Sparks J.S., 2008 Redescription of ponyfishes (Teleostei: Leiognathidae) Shri Lanka and the status of Aurigequula Fowler, 1918. Ceylon Journal of Science (Biological Science) 37(2): 143-161

[17] Márquez, F., Amoroso, R., Florencia, M., Sainz, G., Van der Molen, S., 2010. Shell morphology changes in the scallop Aequipecten tehuelchus during its life span: a geometric morphometric approach. Inter-Research 2010 - www.int-res.com. Vol. 11: 149-155, 2010

[18] Graham

[19] Ducos, M. and Tabugo, S., 2014. Fluctuating asymmetry as an indicator of ecological stress and developmental instability of Gafrarium tumidum (ribbed venus clam) from Maak and Lagoon Camiguin Island, Philippines AACL Bioflux, 2014, Volume $\quad 7, \quad$ Issue 6. http://www.bioflux.com.ro/aacl

[20] Palmer, A. R., Strobeck, C., 1986. Fluctuating asymmetry: measurement, analysis, patterns. Annual Review of Ecology and Systematics 17:391-421. http://dx.doi.org/10.1146/annurev.es.17.110186.002135

[21] Natividad, E. M. C., Dalundong, A. O., Ecot, J., Jumawan, J. H., Torres, M. A. J., Requieron, E. A. 2015. Fluctuating asymmetry as bioindicator of ecological condition in the body shapes of Glossogobiuscelebius from Lake Sebu, South Cotabato, Philippines. AACL Bioflux 8(3):323- 331. 